\title{
Array size and area impact on nanorectenna performance properties
}

\author{
Elif Gul Arsoy, Emre Can Durmaz, Atia Shafique, Meric Ozcan, Yasar Gurbuz*

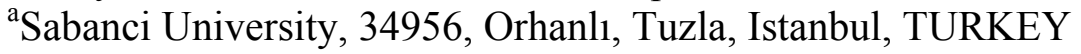 \\ yasar@sabanciuniv.edu \\ +902164839533
}

\begin{abstract}
The metal-insulator-metal (MIM) diodes have high speed and compatibility with integrated circuits (IC's) making MIM diodes very attractive to detect and harvest energy for infrared (IR) regime of the electromagnetic spectrum. Due to the fact that small size of the MIM diodes, it is possible to obtain large volume of devices in same unit area. Hence, MIM diodes offer a feasible solution for nanorectennas (nano rectifiying antenna) in IR regime. The aim of this study is to design and develop MIM diodes as array format coupled with antennas for energy harvesting and IR detection. Moreover, varying number of elements which are $4 \times 4$, and $40 \times 30$ has been fabricated in parallel having $0.040,0.065$ and $0.080 \mu \mathrm{m}^{2}$ diode area. For this work we have studied given type of material; Ti- $\mathrm{HfO}_{2}-\mathrm{Ni}$, is used for fabricating MIM diodes as a part of rectenna. The effect of the diode array size is investigated. Furthermore, the effect of the array size is also investigated for larger arrays by applying given type of material set; $\mathrm{Cr}-\mathrm{HfO}_{2}-\mathrm{Ni}$. The fabrication processes in physical vapor deposition (PVD) systems for the MIM diodes resulted in the devices having high non-linearity and responsivity. Also, to achieve uniform and very thin insulator layer atomic layer deposition (ALD) was used. The nonlinearity $1.5 \mathrm{~mA} / \mathrm{V}^{2}$ and responsivity $3 \mathrm{~A} / \mathrm{W}$ are achieved for $\mathrm{Ti}-\mathrm{HfO}_{2}-\mathrm{Ni} \mathrm{MIM}$ diodes under low applied bias of 400 $\mathrm{mV}$. The responsivity and nonlinearity of $\mathrm{Cr}-\mathrm{HfO}_{2}-\mathrm{Ni}$ are found to be $5 \mathrm{~A} / \mathrm{W}$ and $65 \mu \mathrm{A} / \mathrm{V}^{2}$, respectively. The current level of $\mathrm{Cr}-\mathrm{HfO}_{2}-\mathrm{Ni}$ and $\mathrm{Ti}-\mathrm{HfO}_{2}-\mathrm{Ni}$ is around $\mu \mathrm{A}$ range therefore corresponding resistance values are in $1-10 \mathrm{k} \Omega$ range. The comparison of single and $4 \times 4$ elements revealed that $4 \times 4$ elements have higher current level hence lower resistance value is obtained for $4 \times 4$ elements. The array size is $40 \times 30$ elements for $\mathrm{Cr}-\mathrm{HfO}_{2}$-Ni type of MIM diodes with 40,65 $\mathrm{nm}^{2}$ diode areas. By increasing the diode area, the current level increases for same size of array. The current level is increased from $10 \mu \mathrm{A}$ to $100 \mu \mathrm{A}$ with increasing the diode area. Therefore resistance decreased in the range of $10 \mathrm{k} \Omega$ and nonlinearity is increased from $58 \mu \mathrm{A} / \mathrm{V}^{2}$ to $65 \mu \mathrm{A} / \mathrm{V}^{2}$.
\end{abstract}

Keywords: Metal-Insulator-Metal (MIM) diodes, quantum tunneling, IR harvesting and detection, rectennas.

\section{INTRODUCTION}

The MIM diodes are one of the most promising candidates for sensing and energy harvesting applications due to small size, high speed and operating at room temperature. The MIM diodes were first demonstrated as fast speed operation by Hocker et al. in $1968 \mathrm{~s}^{1}$. Due to the fact that they have smaller size and fast speed rectification, MIM diodes offer solutions for IR detection and energy harvesting. The MIM diodes are already presented in the literature as antenna coupled diodes for energy harvesting applications ${ }^{1}$, wireless power transmission ${ }^{2}$ and detection ${ }^{3}$. The theory of MIM diodes are based on quantum tunneling, the time constant $(\mathrm{RC})$ required to be in the order of femtoseconds.

In this study, our goal is to fabricate MIM diode arrays employed for rectennas to detect and harvest the IR regime of the electromagnetic spectrum. The MIM diodes are composed of insulator layer placed between two metal layers with different work functions to obtain two different barrier heights. It is desired to obtain different barrier height of MIM diode structure as asymmetric barrier formation for MIM diodes. The work functions of the two different type of metals, the electron affinity of the insulator and the band gap of the insulator are the main parameters for energy band diagram shape $^{3}$. The large work function difference of metals in MIM diodes increases to asymmetry and non-linearity ${ }^{4}$. The asymmetric barrier formation can be achieved by the difference of the work function of the metals and the electron affinity value of the insulator. The theory of the MIM diode is based on electron tunneling through thin insulating barrier. For this work insulator layer is selected to obtain the required barrier height and also the metals are selected

Infrared Technology and Applications XLIII, edited by Bjørn F. Andresen, Gabor F. Fulop, Charles M. Hanson,

John L. Miller, Paul R. Norton, Proc. of SPIE Vol. 10177, 101772K · C 2017 SPIE

CCC code: $0277-786 X / 17 / \$ 18 \cdot$ doi: $10.1117 / 12.2263272$

Proc. of SPIE Vol. 10177 101772K-1 
according to obtain asymmetric barrier height. The metals used in this work are $\mathrm{Au}, \mathrm{Ti}, \mathrm{Ni}$, and $\mathrm{Cr}$. Because of the fact that these metals are in line with standard CMOS processes, therefore, they gives widely ease of integration with IC's. The characterization of MIM diodes are carried out by measuring the DC I-V characteristics which are used to extract the device properties such as non-linearity, responsivity and the resistivity of the MIM diodes.

\section{DESIGN AND FABRICATION}

MIM diodes were fabricated on GaAs substrates by using Vistec / EBPG500plusES Electron Beam Lithography system for patterning layers of device. The mask which has been used for lithography is shown in figure 1. The substrate is coated with PMMA resists which are 495K and 950K. After e-beam lithography, the development was carried out in methyl-isobutyl ketone: isopropanol (MIBK:IPA) solution.

The first metal ( $\mathrm{Cr} / \mathrm{Ti}$ ) was deposited by using Physical Vapor Deposition (PVD) system which was used as the bottom electrode. The metal layer was deposited below $8 \times 10^{-6}$ Torr pressure around $1.5 \mathrm{~A} / \mathrm{s}$ rate with thermal evaporation method and then insulator layer was deposited by atomic layer deposition (ALD). The thickness of the (Cr/Ti) layer was $100 \mathrm{~nm}$. And then as an insulator layer $1.5 \mathrm{~nm}$ thickness of $\mathrm{HfO}_{2}$ was deposited. To pattern the substrates lift-off process was performed in acetone (ACE). The second electrode was formed with Nickel (Ni) and on top of Ni gold (Au) was deposited to prevent oxidation of Ni. The cross section of the structure is demonstrated in figure 1.

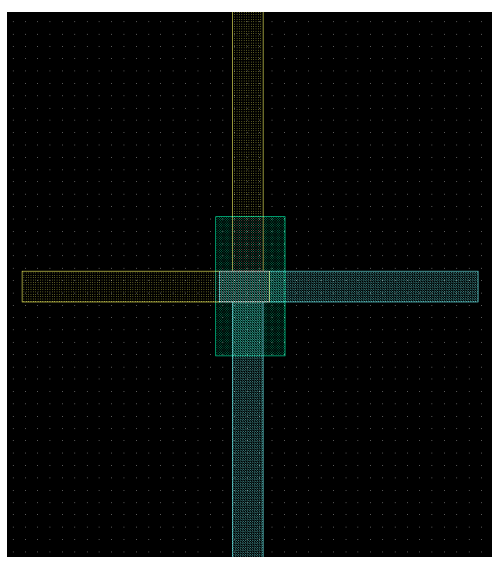

a)

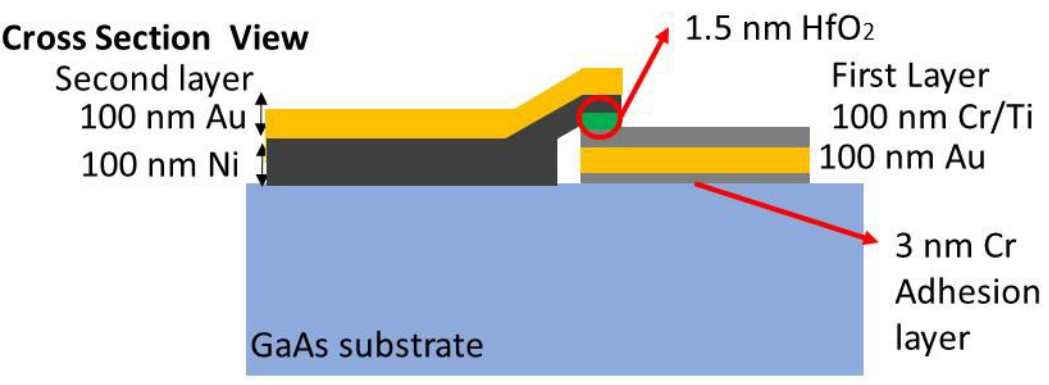

b)

Figure 1. Illustration of MIM diode a) the mask layout for rectenna structure b) cross-section of the diodes for $\mathrm{Cr} / \mathrm{Ti}-\mathrm{HfO}{ }_{2}-\mathrm{Ni}$ diode

\section{RESULTS}

By using Agilent B1500A Semiconductor Parameter Analyzer the I-V characteristics of MIM diodes were measured with DC probe station. The $I-V$ characteristics of the MIM diodes were fitted to $4^{\text {th }}$ order polynomial function. From the measured $I-V$ characteristics resistance, responsivity and non-linearity of MIM diodes were extracted. In figure $2 I-V$ characteristics of the diodes for $\mathrm{Cr} / \mathrm{Ti}-\mathrm{HfO}_{2}-\mathrm{Ni}$ are shown.

The $\mathrm{Cr} / \mathrm{Ti}-\mathrm{HfO}_{2}$-Ni MIM diodes are fabricated with the changing device active area as shown in table 1, in order to see the impact of device area upon the DC resistance of the diodes. The resistance difference with varying array size and the diode area are shown in figure 3. The current level increased with increasing diode are and array size. The difference in the current levels with the same oxide thickness comes from the effective barrier height change with the area of the diode. 

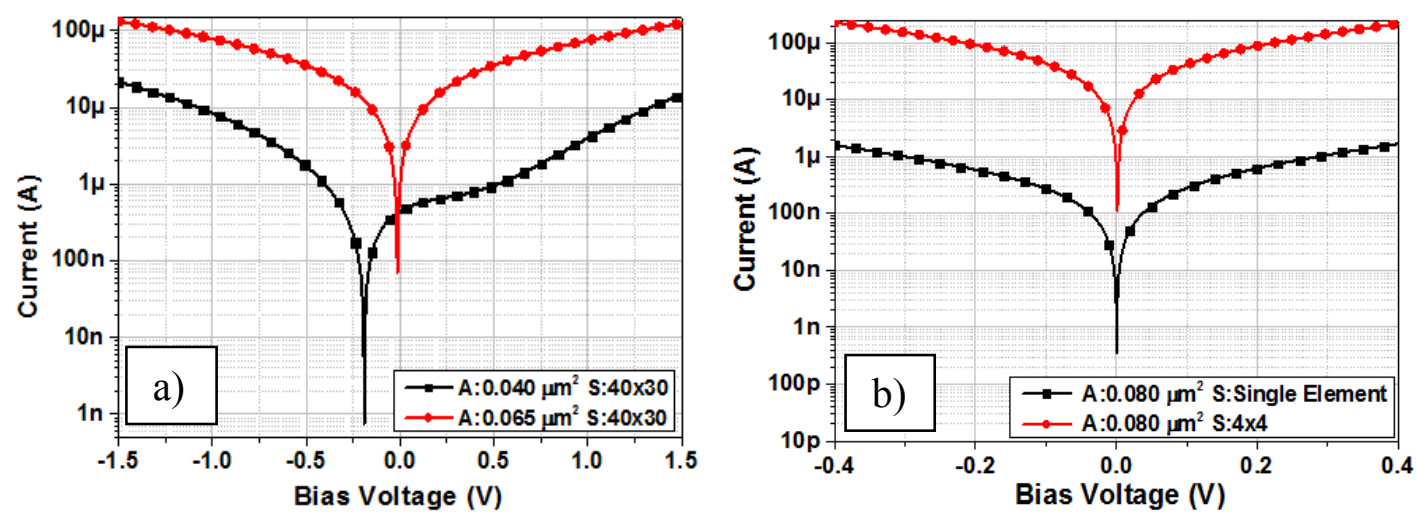

Figure 2. I-V characteristics of fabricated MIM diodes. (a) $\mathrm{Cr}-\mathrm{HfO}_{2}-\mathrm{Ni}$ diodes (b) $\mathrm{Ti}-\mathrm{HfO}_{2}-\mathrm{Ni}$ diodes.

TABLE I

DIODE GEOMETRIC PARAMETERS

\begin{tabular}{lcccc}
\hline Diode Formation & Diode Area & Array Size & Current Level (A) & Insulator Thickness (nm) \\
\hline $\mathrm{Cr}_{\mathrm{H}-\mathrm{HfO}_{2}-\mathrm{Ni}}$ & $0.040 \mu \mathrm{m}^{2}$ & $40 \times 30$ & $140 \mu$ & 1.5 \\
\hline $\mathrm{Cr}-\mathrm{HfO}_{2}-\mathrm{Ni}$ & $0.065 \mu \mathrm{m}^{2}$ & $40 \times 30$ & $34 \mu$ & 1.5 \\
\hline $\mathrm{Ti}-\mathrm{HfO}_{2}-\mathrm{Ni}$ & $0.080 \mu \mathrm{m}^{2}$ & $4 \times 4$ & $204 \mu$ & 1.5 \\
\hline $\mathrm{Ti}-\mathrm{HfO}_{2}-\mathrm{Ni}$ & $0.080 \mu \mathrm{m}^{2}$ & Single Element & $6.2 \mu$ & 1.5 \\
\hline
\end{tabular}
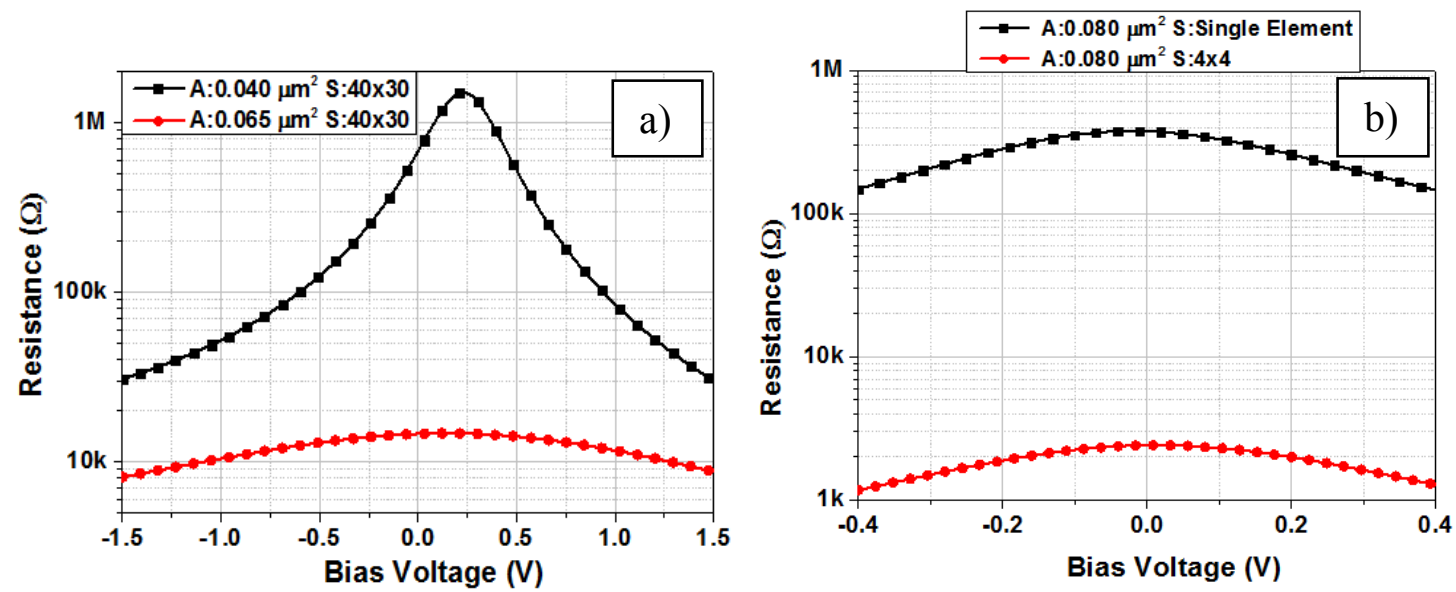

Figure 3. Resistance characteristics of fabricated MIM diodes. (a) Cr-HfO2-Ni diode (b) Ti-HfO2-Ni diode.

According to (1) differential resistances of the fabricated MIM diodes were extracted by using equation (1).

$$
\mathrm{R}=\frac{d V}{d I}
$$

Resistances of fabricated diodes vary from $1 \mathrm{M} \Omega$ to $101 \mathrm{k} \Omega$ with different array size and the diode area. The variation comes from the effective barrier height, diode array size and area of the diodes. 
The responsivity and then non-linearity ${ }^{4}$ of the fabricated MIM diodes were extracted according to (2) and (3) as shown in figure 4 and 5.

$$
\begin{aligned}
& \text { Responsivity }(\beta)=\frac{\left(\frac{d^{2} I}{d V^{2}}\right)}{\left(\frac{d I}{d V}\right)}=R I^{\prime \prime} \\
& \text { Non-Linearity (I") }=\frac{d^{2} I}{d V^{2}}
\end{aligned}
$$

The quantum efficiency is proportional to the responsivity: high responsivity means high quantum efficiency. High responsivity also implies high device efficiency which is obtained for these MIM diodes around the bias voltage of $0 \mathrm{~V}$. In $\mathrm{Cr}-\mathrm{HfO}_{2}$-Ni MIM diodes (Fig. 4), maximum responsivity of $4.95 \mathrm{~A} / \mathrm{W}$ is obtained at $0 \mathrm{~V}$. The non-linearity $2 \mathrm{~mA} / \mathrm{V}^{2}$ and responsivity $3 \mathrm{~A} / \mathrm{W}$ are achieved for Ti- $\mathrm{HfO}_{2}-\mathrm{Ni} \mathrm{MIM}$ diodes under low applied bias of $40 \mathrm{mV}$. The responsivity and nonlinearity of $\mathrm{Cr}-\mathrm{HfO}_{2}-\mathrm{Ni}$ are found to be $5 \mathrm{~A} / \mathrm{W}$ and $65 \mu \mathrm{A} / \mathrm{V}^{2}$, respectively.
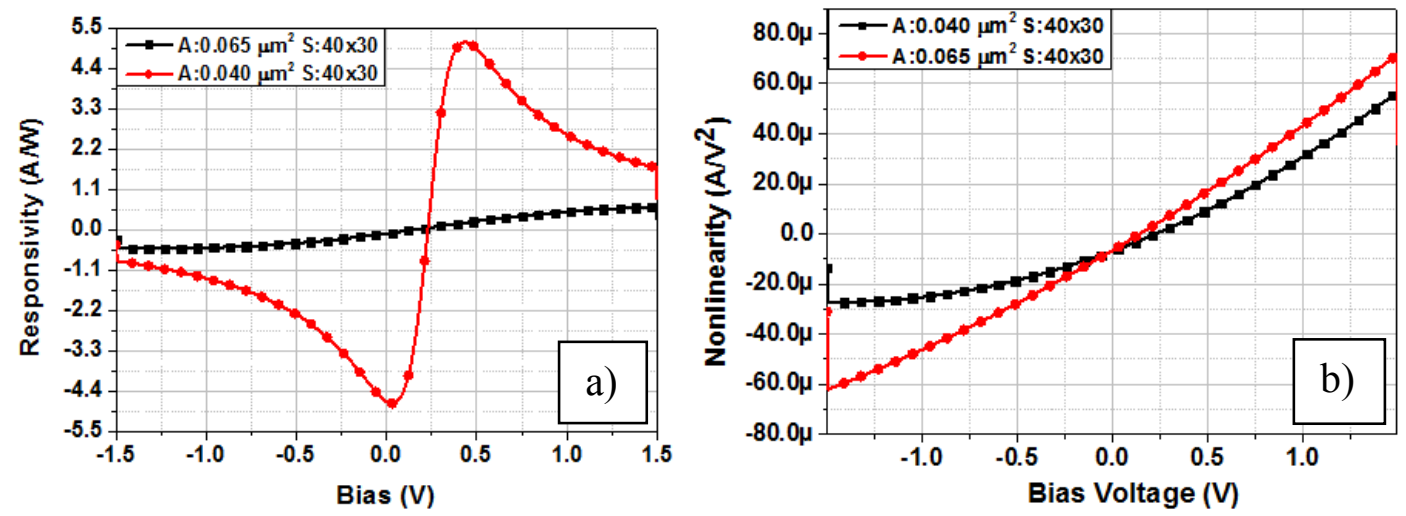

Figure 4. a) Responsivity b) nonlinearity of the of $\mathrm{Cr}-\mathrm{HfO} 2-\mathrm{Ni}$ diodes.
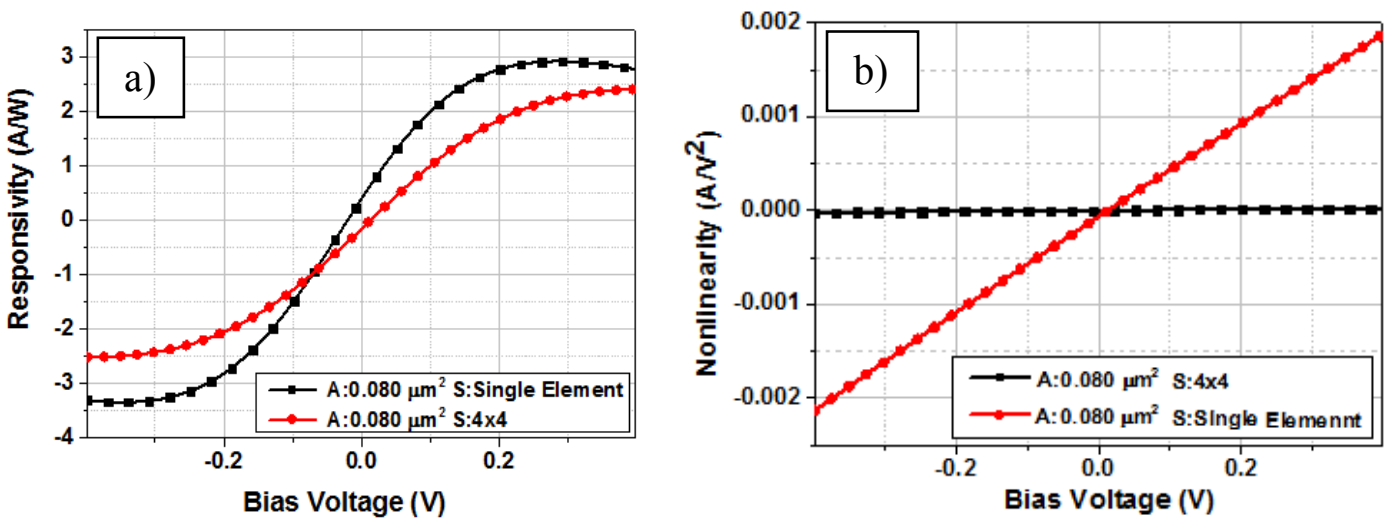

Figure 5. a) Responsivity b) nonlinearity of the of Ti-HfO2-Ni diodes.

The non-linearity is calculated by computing second derivative of current with respect to voltage. Responsivity is related with resistance directly hence lower resistance leads to lower responsivity. 


\section{CONCLUSION}

In this work, MIM diodes with different materials are fabricated on the Ga As substrate. The non-linearity $2 \mathrm{~mA} / \mathrm{V}^{2}$ and responsivity $3 \mathrm{~A} / \mathrm{W}$ are achieved for Ti- $\mathrm{HfO}_{2}-\mathrm{Ni}$ MIM diodes under low applied bias of $40 \mathrm{mV}$. The responsivity and nonlinearity of Cr- $\mathrm{HfO}_{2}-\mathrm{Ni}$ are found to be $5 \mathrm{~A} / \mathrm{W}$ and $65 \mu \mathrm{A} / \mathrm{V}^{2}$, respectively. The resistance of the diodes varies in the range $1 \mathrm{k} \Omega$ to $1 \mathrm{M} \Omega$ depending on device physical aspects. The sizes of the devices are small enough to ease integration

with IC's. These results show that the MIM diodes adhere sufficient potential to be used in applications of IR detection and harvesting.

\section{ACKNOWLEDGMENT}

The authors would like to acknowledge the support for Lockheed Martin University Research Agreement.

\section{REFERENCES}

[1] G. Moddel, [Rectenna Solar Cells], Springer, New York, 3-24 (2013).

[2] W. C. Brown and R. H. George, "Rectification of Microwave Power," IEEE Spectrum, 92-97 (1964).

[3] Rogalsky, A., "Infrared Detectors: Status and Trends" Progress in Quantum Electronics 27, 59-210 (2003).

[4] J.Bean, A. Weeks, and G.D. Boreman, "Performance optimization of antenna-coupled $\mathrm{Al} / \mathrm{AlO}_{\mathrm{x}} / \mathrm{Pt}$ tunnel diode infrared detectors," IEEE Journal of Quantum Electronics 47, 126-135 (2011).

[5] G. Moddel, [Rectenna Solar Cells], Springer, New York, 163-188 (2013). 